$\left(\begin{array}{lll}\text { Jpn. J. Hosp. } & \text { Pharm } \\ \hline \text { 論 } & \text { 文 } \\ 24(3) & 205-213 & (1998)\end{array}\right)$

\title{
難水溶性薬物封入ポリ乳酸マイクロスフェアの新規調製法とその放出性
}

\author{
冨山成章, 中野眞汎* \\ 熊本大学医学部附属病院薬郕部门
}

\section{Preparation and Release Property of Polylactic Acid Microspheres Containing Slightly Water-soluble Drug}

\author{
NARIAKI TOMIYAMA and MASAHIRO NAKANO* \\ Department of Pharmacy, Kumamoto University Hospital $\dagger$
}

$\left(\begin{array}{ll}\text { Received July 9, } 1997 & \\ \text { Accepted November 11, } 1997\end{array}\right)$

Polylactic acid (PLA) microspheres containing theophylline as a slightly soluble representative drug were prepared using the $\mathrm{o} / \mathrm{w}$ emulsion in-water drying method. A high trapping efficiency was observed when polymer solution of high concentration was used and the drug/polymer weight ratio was increased. However, the particle size of the microspheres became extremely large when the high concentration polymer solution was used.

Microspheres with a particle size of $88.6 \mu \mathrm{m}$ were obtained when "sub-emulsification" was performed with the external aqueous phase with an equal specific gravity to the polymer solution. On the other hand, the trapping efficiency of the microspheres was dependent on both the drug encapsulated in the microspheres and the particle size of microspheres.

The release patterns of the drug from the microspheres showed an initial-burst release in all batches. The release rates of the drug from the microspheres prepared with the drug and polymer alone were very small. Therefore, an improvement in the drug release property of the microspheres was examined.

The release rates of the drug from the microspheres increased significantly depending on the amount of ethyl myristate that was incorporated as a release promoter.

Key words — microspheres, polylactic acid, ethyl myristate, release promoter

\section{緒言}

標的指向性と放出制御という製剤設計は, drug delivery system, すなわち DDSの基本的な概念で ある.このような DDS の概念は, 微量で高活性 の生理活性ペプチド類が大量生産されるようにな

$\dagger$ 熊本市本荘1-1-1；1-1-1, Honjo, Kumamoto, 8608556 Japan
ったことや，薬物の副作用が大きな問題となって きたことにより, さらに重要視されてきている. また，薬物の疾患に対する直接作用だけではな く, 患者の QOL やコンプライアンスといったこ とも重要視されてきている。このような状況のも と, 適切な製鼡設計は, 創薬と同じく非常に重要 となり，様々な因子を考慮する必要下にある.

製剤設計，特にDDSの考えを念頭に置いた場 
合，目的を達成できる剤形に，分散系微粒子製剤 が考えられる。具体的には，エマルション，リポ ソーム, マイクロスフェアなどがある。この中で マイクロスフェアとは, 直径が $\mu \mathrm{m}$ 領域の球状高 分子マトリクス内に薬物を含有した製郕である。

マイクロスフェアは高分子マトリクス内を薬物が 徐々に透過すること, 高分子が徐々に分解するこ とにより持続的に薬物を放出する。またマイクロ スフェア表面を修飾することで指向性を持たせる ことも可能である。さらに固体／液体分散系であ るため, 微粉末化が可能であり，そのため長期保 存が可能である.

実際の臨床の場に扔いても, 化学塞栓療法のた めの剂形として応用されている ${ }^{1)}$.

マイクロスフェアの調製に抢いては, 主に相分 離法と液中乾燥法 ${ }^{2)}$ が知られている。液中乾燥 法とは, まずマイクロスフェアの壁物質と薬物か

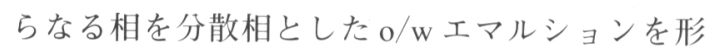
成させ, 徐々に分散相からの溶媒留去, 蒸発によ
りマイクロスフェアを得る方法である(Fig. 1). 特に液中乾燥法は用いる有機溶媒が少ないこと, 操作が簡便なことといったメリットを持つ。これ らのメリットは, 実際の臨床の場においても, 非 常に重要な点と考えられる。

液中乾燥法を用いたマイクロスフェアの調製 は, 封入しようとする薬物の物性により乳化法を 選択する必要がある。すなわち, 脂溶性薬物では $\mathrm{o} / \mathrm{w}$ 乳化法, 水溶性薬物では $\mathrm{w} / \mathrm{o} / \mathrm{w}$ 乳化法によ り調製される。しかしながら従来の方法をそのま ま用いても，難水溶性薬物の効率の良いマイクロ スフェア内への封入は困難であると考えられる。 これは $\mathrm{w} / \mathrm{o} / \mathrm{w}$ 乳化法を用いた場合, 薬物の水へ の溶解度に限度があるために内水相へ効率よく溶 解できないこと，また $\mathrm{o} / \mathrm{w}$ 乳化法を用いた場 合, 油相中にほとんど溶解しないためである。ま た，難水溶性薬物を用いたマイクロスフェアの調 製法に関する報告は少なく，さらに検討の余地が あると考えられた。そこで難水溶性薬物の効率良
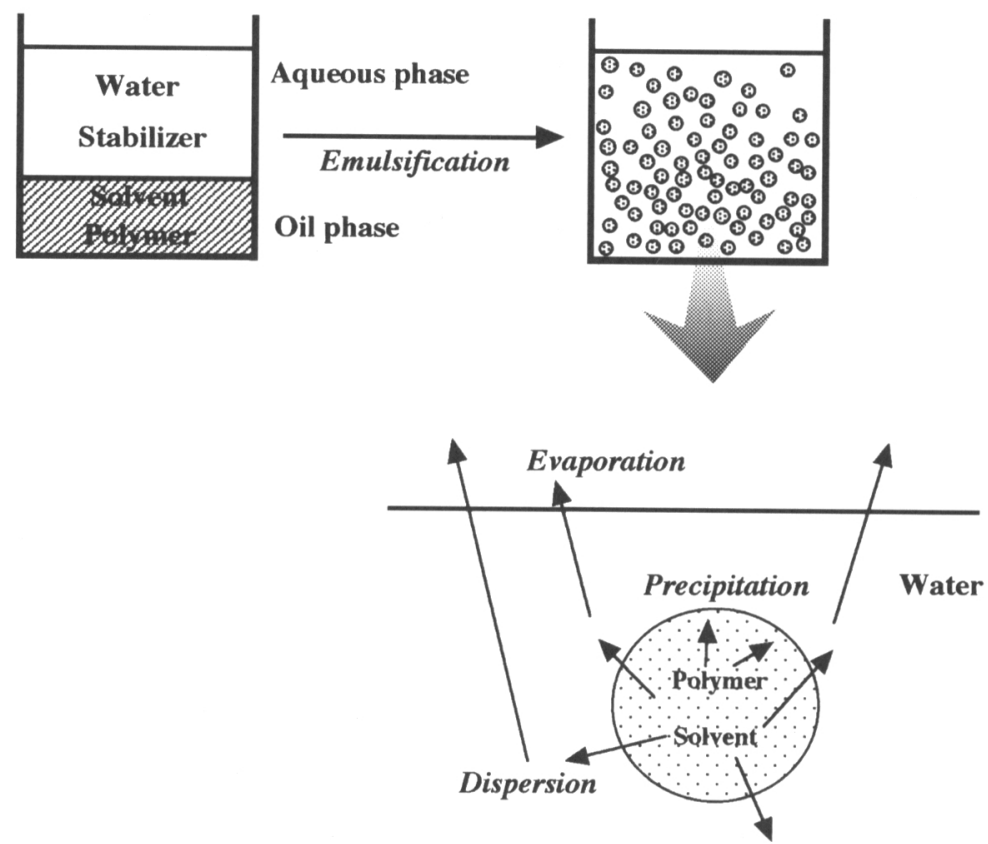

Fig. 1. Schematic Illustration of Preparation of Microspheres with Emulsion in-water Drying Method 
い封入を目的とし，新規調製法の開発とその放出 性についての検討を行った. 水への溶解度に限度 のある薬物の例として, 紫外部吸収を利用して定 量の行いやすいことからテオフィリンを代表薬物 として選択した。 また，高分子としてはマイクロ スフェアの壁物質として汎用される生体内分解性 高分子, ポリ乳酸 (以下 PLA と略す) を用いた。 PLA は生体内で非酵素的に加水分解を受け, 乳 酸となり, 最終的には炭酸ガスと水になって体外 に排出される。このためPLA は臨床的に吸収性 縫合系や骨折固定材として利用されている ${ }^{3)}$.

\section{実験方法}

\section{1. 使用薬物及び試薬}

テオフィリンは和光純薬工業(株)の特級品を用 いた. 生体内分解性高分子である PLA（L 体, 重
量平均分子量 : 25,400$)$ は三井東圧化学 (株), ポ リビニルアルコール (EG-40, 以下 PVA と略す) は日本合成化学工業（株）より供与されたものを 用いた。 ウログラフィン $60 \%$ （日本シエーリング (株)）は市販品を用いた。塩化メチレンは市販の 一級品を蒸留して使用した。ポリソルベート80は 関東化学 (株) の特級品を用いた. パルミチン酸 エチルエステルは和光純薬工業（株）の一級品を 用いた。その他の試薬は市販の特級品をそのまま 使用した。

2. テオフィリン含有マイクロスフェアの調製 (Fig. 2)

PLA 75mg を塩化メチレン $1.5-0.5 \mathrm{ml}$ に溶解し た高分子溶液にテオフィリン15-25mg を加え， プローブ型超音波発生装置（トミー精工，UR-20 P）にて氷浴中で 2 分間懸濁した。このサスペン

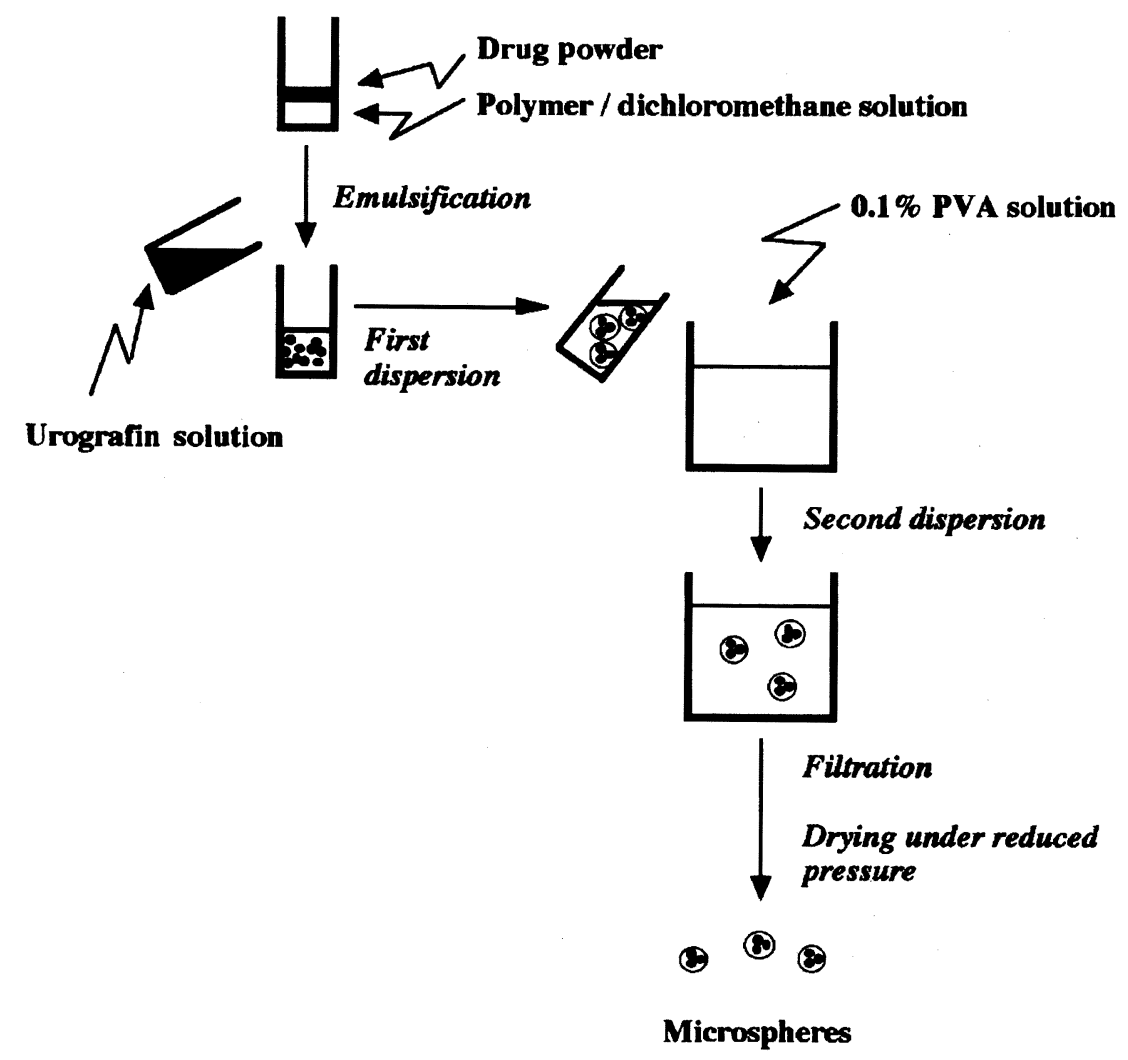

Fig. 2. Preparation of Microspheres with Emulsion in-water Drying Method 
ジョンに高分子溶液とほぼ等比重になるよう調製 した $0.5 \%$ PVA 溶液とウログラフィン溶液の $1 ： 8$ の混液 $1.5 \mathrm{ml}$ を加え,ボルテックスミキ サー(MS 1 Minishaker, 表面突起型, IKA Works, または Multi Flash Mixer，表面平面型，三田村理 研工業）にて乳化した（1 次分散）。このエマル ションを，700rpm で擋拌している0.1\% PVA 溶 液 $100 \mathrm{ml}$ 中に分散した (2 次分散)。約 2 時間後, 生成したマイクロスフェアをろ取し，精製水で十 分洗浄した後，減圧下で 2 日間乾燥した.

ミリスチン酸エチルエステルを添加したテオ フィリン含有マイクロスフェアは，まずミリスチ ン酸エチルエステル22.5-37.5mg と PLA75mg を 秤量し，塩化メチレン $500 \mu \mathrm{l}$ を加え高分子溶液と した. $20 \mu \mathrm{m}$ の篩で篩過したテオフィリン $25 \mathrm{mg}$ を加え, プローブ型超音波発生装置にて氷浴中で 2 分間㷂濁した。 1 次分散は Multi Flash Mixer を 用い，5秒間行った。その他は無添加群に準じ た.

3. マイクロスフェアの粒子径測定

マイクロスフェアの粒子径は，無作為に選んだ 50-100個のグリーン径を光学顕微鏡により測定 し，算術平均径を平均粒子径とした。

\section{4. 、イクロスフェア内薬物含有量の測定}

スクリュー瓶にマイクロスフェア約 $3 \mathrm{mg}$ を秤 量した後, 塩化メチレン $2 \mathrm{ml}$ を加えてマイクロ スフェアを完全に溶解させた。これに精製水 5 $\mathrm{ml}$ を加え, 振盪機にて10分間水平方向に振盪し た. $3000 \mathrm{rpm}, 4{ }^{\circ} \mathrm{C}$ で10分間遠心分離し，水相を 適宜希釈し，テオフィリン濃度を分光光度計（島 津製作所，UV-240）を用いて $271 \mathrm{~nm}$ での吸光度 を測定し, 以下の值を算出した.

1) Drug content (薬物封入量, \%)：マイク ロスフェア $1 \mathrm{mg}$ 中に占める薬物の割合で, 測定 値より算出.

2 ) Calculated drug content（理論的薬物封入 量，\%：調製時に用いた量より，理論的にマイ クロスフェア $1 \mathrm{mg}$ 内に含有される薬物の割合を 算出.
3 ) Trapping efficiency（封入効率，\%)：薬物 の封入効率で Drug content/calculated drug content とした值を百分率として算出.

\section{In vitro 放出試験}

バイアル瓶にマイクロスフェア約 $5 \mathrm{mg}$ を秤量 した後, ポリソルベート $80 を 0.1 \%$ 含有した生理 食塩液 $10 \mathrm{ml}$ を加えた。このバイアル瓶を $37^{\circ} \mathrm{C}$ の 恒温振盪槽中で振燙した。経時的に放出液を採取 し，新しい放出液を補充した。採取した放出液を 分光光度計（島津製作所 UV-240）を用いて測定 波長 $271 \mathrm{~nm}$ での吸光度を測定し, 薬物放出量を 算出した.

\section{結果及び考察}

1. $\mathrm{o} / \mathrm{w}$ 乳化型/液中乾燥法によるテオフィリン 含有マイクロスフェアの調製法の検討

1-1 封入効率と粒子径に及ぼす処方および 調製条件の影響

当初, 粒子径を小さくする目的でPLAの溶媒 である塩化メチレンの量を $1.5 \mathrm{ml}$ として調製した が，封入効率は約 $8 \%$ と薬物はほとんど封入され なかった. そこで塩化メチレンの量を $1 \mathrm{ml}, 0.5$ $\mathrm{ml}$ と減少したところ, 封入効率は大幅に向上し た。しかし，粒子径は大幅に増加した（Table 1)。これは高分子濃度の増加により, 粘度が高 くなり，薬物の漏洩が減少したためと考察され る。なお，塩化メチレンの残留は測定していな い. 極めて揮発性であることから，十分取り除か れていると考えられるが，ヒトへの投与が必要な 段階では検討が必要と考えられる。

そこで，高分子溶液とほぼ等しい比重の水相を 添加する補助的な乳化，すなわち 1 次分散を行 い，その後 PVA 溶液に分散させる（2 次分散） という二段階の乳化法を行った。当初の 1 次分散 の擋拌条件 (IKA Works, MS 1 Minishaker を使 用）において，粒子径は 1 次分散時間が 20 秒以上 ではほぼ一定の值を示した．封入効率に関して も，若干の低下があったが，20秒では約70\%であ った (Table 2). 
Table 1. Effect of PLA Concentration on Pharmaceutical Parameters of PLAmicrospheres Containing Theophylline (Drug : polymer $=1: 5$ )

\begin{tabular}{ccccc}
\hline & & F 1 & F 2 & F 3 \\
\hline \hline Dichloromethane & $(\mathrm{ml})$ & 1.5 & 1.0 & 0.5 \\
\hline Yield & $(\%)$ & 71.3 & 74.3 & 59.9 \\
Calculated drug content & $(\%)$ & 16.7 & 16.7 & 16.7 \\
Drug content* & $(\%)$ & $1.4 \pm 0.08$ & $4.4 \pm 0.02$ & $13.5 \pm 1.0$ \\
Trapping efficiency* & $(\%)$ & $8.3 \pm 0.5$ & $26.8 \pm 0.1$ & $81.2 \pm 5.9$ \\
Particle size* & $(\mu \mathrm{m})$ & $130.8 \pm 33.6$ & $236.6 \pm 81.4$ & No measurement \\
\hline
\end{tabular}

* Each value represents the mean \pm SD.

Table 2. Effect of 1st Dispersion Time on Pharmaceutical Parameters of PLAmicrospheres Containing Theophylline (Drug : polymer $=1: 5$ )

\begin{tabular}{ccccccc}
\hline & & F 3 & F 4 & F 5 & F 6 & F 7 \\
\hline \hline 1st dispersion time & $(\mathrm{sec})$ & $\mathbf{0}$ & 10 & 20 & 30 & 40 \\
\hline Yield & $(\%)$ & 59.9 & 86.2 & 72.6 & 79.3 & 75.7 \\
Calculated drug content & $(\%)$ & 16.7 & 16.7 & 16.7 & 16.7 & 16.7 \\
Drug content* & $(\%)$ & $13.5 \pm 1.0$ & $13.2 \pm 0.3$ & $11.57 \pm 0.5$ & $11.29 \pm 10.0$ & $9.4 \pm 0.7$ \\
Trapping efficiency* * & $(\%)$ & $81.2 \pm 5.9$ & $79.0 \pm 1.9$ & $69.4 \pm 2.9$ & $67.8 \pm 5.8$ & $56.4 \pm 4.2$ \\
Particle size* & $(\mu \mathrm{m})$ & No measurement $232.4 \pm 74.4$ & $139.3 \pm 44.8$ & $112.6 \pm 41.0$ & $129.7 \pm 36.0$ \\
\hline
\end{tabular}

* Each value represents the mean $\pm \mathrm{SD}$.

Table 3. Effect of 1st Dispersion and Drug Powder through 20- $\mu \mathrm{m}$ Mesh on Pharmaceutical Parameters of PLA-microspheres Containing Theophylline (Drug : polymer $=1: 5$, PLA concentration $=20 \%$ )

\begin{tabular}{cccccc}
\hline & & F 8 & F 9 & F 10 & F 11 \\
\hline \hline & & \multicolumn{2}{c}{ Raw drug powder } & \multicolumn{2}{c}{$\begin{array}{c}\text { Drug powder through } \\
\text { 20-pm mesh }\end{array}$} \\
\hline 1st dispersion time & $(\mathrm{sec})$ & 5 & 10 & 5 & 10 \\
\hline Yield & $(\%)$ & 76.3 & 69.6 & 73.1 & 79.2 \\
Calculated drug content & $(\%)$ & 16.7 & 16.7 & 16.7 & 16.7 \\
Drug content* & $(\%)$ & $6.2 \pm 1.3$ & $6.3 \pm 0.3$ & $7.2 \pm 0.4$ & $7.0 \pm 0.5$ \\
Trapping efficiency* & $(\%)$ & $36.9 \pm 26.2$ & $37.6 \pm 1.6$ & $43.4 \pm 2.1$ & $41.7 \pm 0.3$ \\
Particle size* & $(\mu \mathrm{m})$ & $80.5 \pm 26.2$ & $79.0 \pm 32.9$ & $82.6 \pm 26.3$ & $64.1 \pm 23.2$ \\
\hline
\end{tabular}

* Each value represents the mean \pm SD.

また，粒子徍を $100 \mu \mathrm{m}$ 以下にするために 1 次 分散の擋拌速度を上げる目的でボルテックスミキ サーを変更した(Multi Flash Mixer, 三田村理研工 業)。また，封入効率を増加させる目的でテオ
フィリン粉末を $20 \mu \mathrm{m}$ の篩にて篩過したものを使 用した.これにより粒子径は約 $65 \mu \mathrm{m}$ まで低下し たが封入効率も大幅に低下した（Table 3$)$ ）ま た，F 9 とF11を比較した場合, F11の方が封入効 
率は増加し，粒子径は低下した。粒子径の低下 は，節過したテオフィリン粉末を用いたことで， 大きなテオフィリン粉末が除去され，擋找に対す る障壁が小さくなり, 効率良く分散されたためと 考えられる。

また, PVA 濃度を従来の $0.1 \%$ か $1.0 \%$ と增 加した。剪断力の増加による粒子径の低下を期待

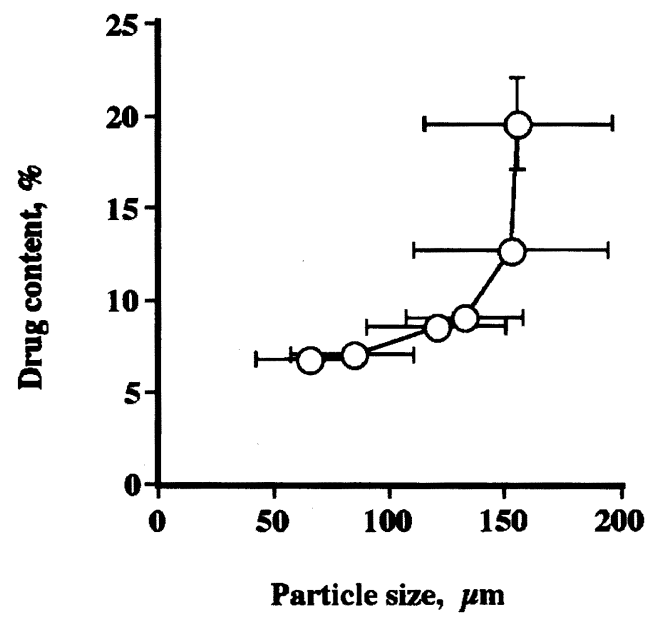

Fig. 3. Relationship between Particle Size and Drug Content of PLA-microspheres Containing Theophylline Prepared with Drug Powder through $20 \mu \mathrm{m}$ Mesh

*Each point represents the mean $\pm \mathrm{SD}$.
したが，封入効率，粒子径ともに大きな変化は認 められなかった。

これらの結果から, 本調製法において, マイク ロスフェアの粒子径を低下させると薬物含量も低 下する傾向が明らかとなった（Fig. 3 ).

1-2 封入効率と粒子径に及ぼすテオフィリ ンと PLA の組成比の影锌

テオフィリンと PLA の組成比について検討し た. PLAの量を一定とし, テオフィリンと PLA の組成比を $1 ： 5 ， 1 ： 4 ， 1 ： 3$ と変えていく と, テオフィリン含有量, 封入効率とも増加する 傾向を示した (Table 4). 調製時, テオフィリ ンは粉末状態で高分子溶液中にほぼ均一に分散し ていると考えられる. 薬物量が増大すると, 分散 しているテオフィリン粉末間の組み方がより複雑 となり, 薬物の外水相への漏洩を妨げていると考 えられる。

そこで高い薬物含量と $100 \mu \mathrm{m}$ 以下の粒子径を もち，ある程度の封入効率をもつマイクロスフェ アを調製するために，テオフィリンとPLAの組 成比を $1: 3$ とし，1 次分散に擋找速度の速い Multi Flash Mixerを用いて調製した. 封入効率は 約66\%と若干低下するものの, 薬物含量が $15.8 \%$, 粒子径が約 $90 \mu \mathrm{m}$ のマイクロスフェアを 調製することができた（Table 5$)$.

Table 4. Effect of Amount of Drug on Pharmaceutical Parameters of PLAmicrospheres Containing Theophylline (PLA concentration=20\%)

\begin{tabular}{|c|c|c|c|c|}
\hline & & F 12 & F 13 & F 14 \\
\hline Amount of drug & (mg) & 15.0 & 18.8 & 25.0 \\
\hline Drug : Polymer ( & (mg : mg) & $1: 5$ & $1: 4$ & $1: \mathbf{3}$ \\
\hline Yield & $(\%)$ & 72.6 & 79.0 & 76.9 \\
\hline \multicolumn{2}{|c|}{ Calculated drug content $(\%)$} & 16.7 & 20.0 & 25.0 \\
\hline Drug content* & $(\%)$ & $9.3 \pm 0.2$ & $12.9 \pm 0.5$ & $19.7 \pm 2.5$ \\
\hline Trapping efficiency* & (\%) & $55.9 \pm 1.4$ & $64.5 \pm 2.6$ & $78.8 \pm 10.0$ \\
\hline Particle size* & $(\mu \mathrm{m})$ & $131.0 \pm 25.4$ & $150.8 \pm 42.0$ & $154.2 \pm 40.7$ \\
\hline
\end{tabular}

* Each value represents the mean \pm SD. 
Table 5. Effect of 1st Dispersion Condition on Pharmaceutical Parameters of PLAmicrospheres Containing Theophylline (Drug : polymer $=1: 3$ )

\begin{tabular}{cccc}
\hline & & F 14 & F 15 \\
\hline \hline 1st dispersion condition & & Mild Vortex mixing & Vigorous Vortex mixing \\
1st dispersion time & $(\mathrm{min})$ & 20 & 5 \\
\hline Yield & $(\%)$ & 76.9 & 80.4 \\
Calculated drug content & $(\%)$ & 25.0 & 25.0 \\
Drug content* & $(\%)$ & $19.7 \pm 2.5$ & $15.8 \pm 0.9$ \\
Trapping efficiency* & $(\%)$ & $78.8 \pm 10.0$ & $63.4 \pm 3.7$ \\
Particle size* & $(\mu \mathrm{m})$ & $154.2 \pm 40.7$ & $88.6 \pm 23.6$ \\
\hline
\end{tabular}

* Each value represents the mean \pm SD.

\section{2. マイクロスフェアからの薬物放出性}

今回調製したマイクロスフェアからのテオフィ

リンの放出プロファイルを Fig. 4 に示す.

マイクロスフェアからのテオフィリンの放出 は，初期の速い放出を持つ二相性の放出プロファ イルを示した。 8 日間でのマイクロスフェアから のテオフィリンの放出は若干の放出が見られただ けであり，薬物封入量が大きいほど，また粒子径 が小さいほど大きくなる傾向を示した。一般にマ イクロスフェアからの薬物放出機構は，マイクロ

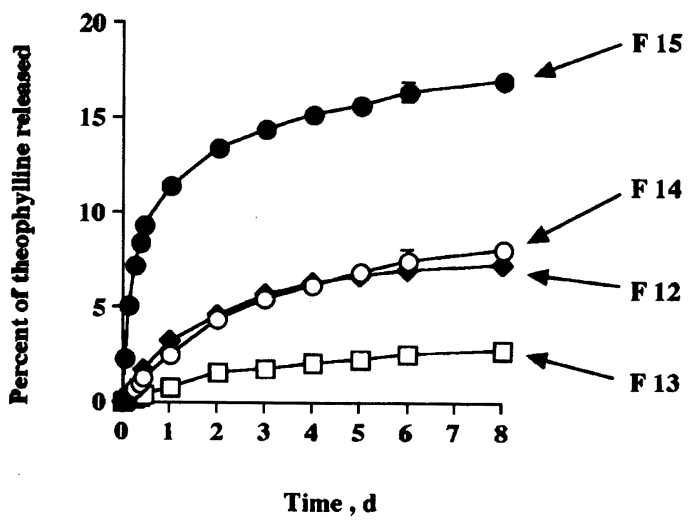

Fig. 4. Release Profiles of Theophylline from PLA-microspheres in Normal Saline Containing $0.1 \%$ Polysorbate 80 *Each point represents the mean \pm SEM $(n=3)$.
スフェアマトリクス内への水の浸透に伴う薬物拡 散や高分子の分解によるものとされている ${ }^{4)}$. 今 回用いたPLA は分子量が25,400と比較的大き い.このため 8 日間で PLA はほとんど分解して いないと考えられ ${ }^{5)}$, マイクロスフェア表面付近 のテオフィリンのみがマトリクス中を拡散し, 放 出したと考えられる.

3. パルミチン酸エチルエステルの放出促進剤と しての添加による薬物封入効率, ならびに薬物放 出への影響

薬物の放出が遅いことが明らかとなったため， 脂肪酸エステルであるミリスチン酸エチルエステ ルの添加による放出促進を試みた。

本研究室では, 放出性の改善を目的として脂肪 酸エチルエステルの添加により，放出性が制御可 能なことを報告している ${ }^{6)}$. 脂肪酸エチルエステ ルの炭素鎖が長いほど, 高い放出促進効果が期待 できる. 今回，これらの結果から高い放出促進が 期待された炭素数14の脂肪酸エステル，ミリスチ ン酸エチルエステルの添加を試みた。脂肪酸エス テル類は人体に対して安全な可塑剤と考えられる が, 臨床へ応用の際には, 生体適合性についての 検討が必要と考えられる。

薬物封入量は添加物の処方量増加に伴い低下し た（Table 6). Table 1 の結果から, 高分子溶液 の粘度が高いほどマイクロスフェアへの薬物の封 
Table 6. Effect of Amount of Ethyl Myristate on Pharmaceutical Parameters of PLA-microspheres Containing Theophylline

\begin{tabular}{ccccc}
\hline & & F 15 & F 16 & F 17 \\
\hline \hline Level of ethyl myristate & (\% of polymer) & 0 & 30 & 50 \\
\hline Yield & $(\%)$ & 80.4 & 70.9 & 68.0 \\
Calculated drug content & $(\%)$ & 16.7 & 20.0 & 25.0 \\
Drug content* & $(\%)$ & $15.8 \pm 0.9$ & $16.2 \pm 0.4$ & $14.4 \pm 0.2$ \\
Trapping efficiency* $_{\text {Particle size* }}$ & $(\%)$ & $63.4 \pm 3.7$ & $64.7 \pm 1.7$ & $57.5 \pm 3.7$ \\
Po & $(\mu \mathrm{m})$ & $88.6 \pm 23.6$ & $99.4 \pm 28.0$ & $80.3 \pm 22.6$ \\
\hline
\end{tabular}

* Each value represents the mean \pm SD.

入効率は良くなる傾向を示した．このことから， ミリスチン酸エチルエステルの添加による封入効 率の低下は，高分子溶液の粘度が低下したためと 推測される.

こうして調製したマイクロスフェアからのテオ フィリンの放出プロファイルを Fig. 5 に示す.

ミリスチン酸エチルエステルの添加量が多いほど 高い放出性を示した。また，ミリスチン酸エチル エステル添加群でも無添加時と同様に，初期に大 きな放出を持つ二相性の放出プロファイルを示し た。放出性は，ミリスチン酸エチルエステルの添

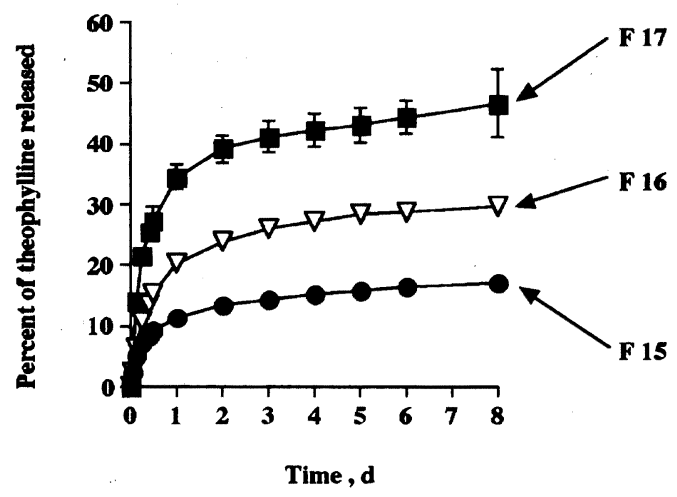

Fig. 5. Release Profiles of Theophylline from PLAmicrospheres Containing Ethyl Myristate in Normal Saline Containing 0.1\% Polysorbate 80

*Each point represents the mean \pm SEM (n $=3$ ).
加量が多いほど高い放出性を示したが，主に初期 バーストを促進し, その後の放出はあまり変わら ないものであった。ミリスチン酸エチルエステル はPLA と同様に塩化メチレンに溶解する。この ためマイクロスフェア内の構造はPLA とミリス チン酸エチルエステルから成るマトリックス中に テオフィリンが分散した状態であると考えられ る。また, ミリスチン酸エチルエステルなどの脂 肪酸エステルによる放出促進機構は, 脂肪酸エス テルにより形成された細孔中に薬物が溶解し拡散 すること, 脂肪酸エステルが抜けた後の細孔に水 が浸透することで薬物放出を促進すると考えられ ている ${ }^{6)}$.これらのことより，テオフィリンはミ リスチン酸エチルエステルに不溶であるために， 主に後者の機構により放出促進効果が得られると 考察される.しかしながら，ミリスチン酸エチル エステルによる放出促進効果が, 主に初期の放出 を増大させたのは，放出液のマトリックス内への 拡散がマイクロスフェア表面付近に限られるため と考察される.

$$
\text { まとめ }
$$

今回, 難水溶性薬物であるテオフィリンのマイ クロスフェア化を液中乾燥法にて試みた。高濃度 の高分子溶液を用いること，1次分散を行うこ と, また処方変更により, 封入効率が約63\%, 粒 子径 $100 \mu \mathrm{m}$ 以下のマイクロスフェアが調製可能 
であった。こうして調製したマイクロスフェアか らの薬物放出は低いものであり, 放出性は薬物封 入量と粒子径に依存する傾向が認められた。さら に, 放出性改善を目的としてミリスチン酸エチル エステルの添加を試みた。ミリスチン酸エチルエ ステルを含有したマイクロスフェアからの薬物放 出は, 初期バーストを示すものの, 放出率は大幅 に増加した。

このように薬物封入量, 封入効率については大 幅な改善が認められたものの, 放出性に関して は, いまだ多くの改善の余地があると考えられ る。

\section{引用文献}

1）市原知文, “動注がん化学療法一基礎と臨床—”, 田口錢男, 中村仁信編, 癌と化学療法社, 東京, 1986, pp. 334-341.

2) N.Wakiyama, K.Juni and M.Nakano, Chem. Pharm. Bull., 29, 3363-3368 (1981).

3）筏義人, “生分解性プラスチックハンドブック”, 土肥義治編, エヌ・ティー・エス, 東京, 1995, pp. 279-291.

4) 部谷敏郎, 岡田弘晃, 小川泰亮, 膜, 20, 270-275 (1995).

5) R.A.Miller, J.M.Brady and D.E.Cutright, J. Biomed. Mater. Res., 11, 711-719 (1977).

6) K.Juni, J.Ogata, N.Matsui, M.Kubota and M. Nakano, Chem. Pharm. Bull., 33, 1609-1738 (1985). 